\title{
Genetic polymorphisms associated with common symptoms experienced by breast cancer patients.
}

\author{
Murtala B. Abubakar ${ }^{1,2 *}$, Siew H. Gan ${ }^{3}$ \\ ${ }^{1}$ Human Genome Centre, School of Medical Sciences, Universiti Sains Malaysia, Malaysia \\ ${ }^{2}$ Department of Physiology, Faculty of Basic Medical Sciences, College of Health Sciences, Usmanu Dan Fodiyo \\ University, PMB 2254 Sokoto, Nigeria \\ ${ }^{3}$ School of Pharmacy, Monash University Malaysia, Jalan Lagoon Selatan, 47500 Bandar Sunway, Selangor, Malaysia
}

\begin{abstract}
The recent advances have led to a considerable increase in the proportion of breast cancer survivors, however, majority of them experience symptoms such as fatigue, pain, depression and sleep disturbances that impair their Quality of Life (QOL) significantly. In addition, a significant inter-individual variability in QOL of breast cancer patients exists which has been partly attributed to genetic variations. However, details of how these variations are influenced by genetic factors remain largely unknown. Therefore, detecting patients with greater susceptibility to reduced QOL using genetic markers may help in designing intervention strategies for personalized medicine. Although limited number of studies have reported on the associations between genetic polymorphisms and QOL, cytokine gene polymorphisms has consistently been linked to increased susceptibility to the development of common symptoms (fatigue, pain, depression and sleep disturbances) in breast cancer patients. More interestingly, these symptoms share some common molecular pathways making it possible to consider them as symptom cluster. In this review, the relationship between genetic variation and common symptoms among breast cancer patients is discussed. In order for genetic factors to be integrated into clinical practice and nursing care of breast cancer patients with impaired QOL, additional studies are encouraged to understand the underlying molecular mechanisms involved in the development of these symptoms and their impact on QOL for identification of patients based on the presence of a symptom cluster using genetic biomarkers.
\end{abstract}

Keywords: Breast cancer, Genetic polymorphisms, Quality of life, Fatigue, Depression, Pain, Sleep disturbances. Accepted on December 18, 2017

\section{Introduction}

Overall, breast cancer is the second most common cancer and by far the most frequent cancer in women with an estimated 1.7 million cases reported in 2012. However, in terms of mortality, it ranks $5^{\text {th }}$ as a result of fairly favourable prognosis [1]. The recent advances in early diagnosis and treatment of breast cancer have led to a significant increase in the number of survivors with a five year survival rate climbing to $90 \%$ [2]. Nevertheless, currently, a significant proportion of breast cancer survivors suffer lot of consequences that considerably impair their quality of life (QOL) among which include psychological distress [3,4], fatigue and sleep disturbances [5], as well as pain [6]. These symptoms are believed to be related to one another with a recent data suggesting that they can manifest as a symptom cluster [7-9] that can cause significantly impaired QOL among cancer patients [10-12].

With regards to management of breast cancer related symptoms, most attention in the past has been focused on individual symptoms or more recently on symptom cluster; nevertheless QOL assessment has recently been recognized as an important patient-reported outcome in breast cancer and other oncology patients [13-16]. To date, the reported interindividual variability in QOL of breast cancer patients $[17,18]$ has not been fully explained by the socio-demographic factors or biological characteristics of the disease and/or its treatment [19-23]. There exist a number of reports to support the fact that an individual's intrinsic factors including genetic factors may play a role in the inter-individual differences in QOL [24-26].

A number of studies have reported a significant impairment of QOL that is associated with fatigue, pain, depression and sleep disturbance among cancer patients which constitute their major complaints $[3,27-30]$. In view of the fact that these symptoms are the most common domains considered in assessing QOL, understanding their association with genetic variation and its impact on inter-individual differences in QOL through high quality studies was recently advocated [31]. Although some 
studies have recently reported on the association between cytokine gene polymorphisms and QOL in lung cancer patients $[32,33]$ as well as patients with cancers of the breast, prostate, lung and brain and their family caregivers [34], at the time of this review, no study has specifically reported on the impact of genetic polymorphisms on QOL in breast cancer patients. A closely related study has revealed an association between nuclear factor kappa beta 2 (NFKB2) gene and three (physical, social and spiritual) of the four QOL domains in oncology patients and their family caregivers [35], thus further corroborating the potential role of gene polymorphisms in inter-individual differences in QOL.

In this article, the impacts of genetic variation on the major symptoms commonly experienced by breast cancer patients and are believed to significantly influence the QOL of patients are reviewed with a view to providing insight on possible identification of patients with higher risk of QOL impairment using genetic markers.

\section{Fatigue and Energy Levels}

Pro-inflammatory cytokines have been suggested to play a role in activating the central and autonomic nervous systems to trigger fatigue and other behavioural symptoms in both cancerrelated fatigue as well as in inflammatory diseases-related fatigue [36,37]. A larger body of literature also suggests that there is an association between fatigue and inflammatory markers among breast cancer patients and survivors [38-43]. A number of Single Nucleotide Polymorphisms (SNPs) in proinflammatory cytokines have been reported to be linked with breast cancer susceptibility and prognosis [44-48] as well as the development of treatment-related adverse effects $[49,50]$. Some evidences have emerged from recent literatures that the energy level in an individual may be considered as a distinct but related symptom to fatigue [51-54]. Therefore, owing to the relationship between fatigue and energy level, it is hypothesized that a significant number of cytokines and neurotransmitters [55-58] could play a vital role in the development of these related symptoms.

\section{Cytokine genes and fatigue and energy}

An earlier finding in a small cohort of breast cancer survivors suggested that patients harbouring the heterozygous or homozygous rare T variant allele of $I L 1 B-511 \mathrm{C}>\mathrm{T}$ (rs16944) had higher odds of not having fatigue while those carrying the homozygous $\mathrm{G} / \mathrm{G}$ or $\mathrm{C} / \mathrm{C}$ variants of IL6-174 G $>\mathrm{C}$ (rs1800795) are more likely to suffer from fatigue [59]. The study reported that $I L 1 B-511$ appeared to be a more reliable marker of fatigue than IL6-174 because it remained significant even after controlling for demographic and clinical confounders which was not the case with the other SNP (IL6-174) that was confounded by age and some clinical variables. Nevertheless, the results of this study were not strongly conclusive due to the 1) relatively small sample size used and 2) lack of a control group of women without breast cancer which would have provided more information on whether the association between cytokines SNPs fatigue was specific to breast cancer patients and/or treatment of the disease. Consequently, to address this limitation, Reinertsen et al. conducted a similar study in a larger cohort of breast cancer survivors in two parts with the second part categorising the patients in to persistent- and never-fatigued subjects [60]. Their study did not find any significant association between fatigue and the above SNPs (rs16944 and rs1800795) as previously reported by ColladoHidalgo et al. [59]. Several reasons could contribute to the disparity seen i.e. the 1) relatively small sample size used by Collado-Hidalgo et al., 2) use of different fatigue measures, 3) differences in the types of subjects used; where the breast cancer women recruited by Collado-Hidalgo et al. consisted of those diagnosed with early-stage breast cancer stages 0-II [59], Reinertsen et al. included stages II and III breast cancer subjects [60]. Furthermore, the depression scores in ColladoHidalgo et al. were significantly higher among the fatigued subjects. After correcting for depression, although the relationship between fatigue and rs16944 in the IL1B-511 became near-significant $(\mathrm{p}=0.052)$ it continued to show significance after controlling for other variables; and after adjusting for age and several treatment-related factors, the relation between fatigue and rs 1800795 in the IL6-174 became insignificant [59]. Therefore, at this stage, the roles of rs 16944 and rs 1800795 as predictors of fatigue in breast cancer patients can be considered as inconclusive especially due to the disagreement between the two studies above and the fact that only a limited number of pro-inflammatory SNPs were investigated, leaving room for the possibility of identification of novel SNPs in the inflammatory pathways in future.

To further clarify the above contradictions, Bower et al. examined $T N F-308 \mathrm{G}>\mathrm{A}$ (rs1800629) together with IL1B-511 $\mathrm{C}>\mathrm{T}$ and IL6-174 $\mathrm{G}>\mathrm{C}$ discussed above among women with early-stage breast cancer [61]. Their results demonstrated that fatigue was significantly associated with both $T N F-308$ and IL6-174 but was not associated with $I L 1 B-511 \quad \mathrm{C}>\mathrm{T}$. The addition of $T N F-308$ previously established to be associated with fatigue among oncology patients undergoing treatment [62] might have enhanced the sensitivity of Bower et al. study to detect SNPs association with fatigue. Although this recent study [61] suggests that breast cancer patients harbouring certain variants of cytokines genes may be at higher risk of developing fatigue, it still cannot be concluded at this point if genetic variants of pro-inflammatory cytokines could serve as clinical genetic biomarkers to predict breast cancer patients who have higher risk of having fatigue. Indeed, more studies involving additional genetic variants especially in a larger cohort of different ethnicities are needed.

A more comprehensive study examining the impact of genetic variation in cytokines and their receptors on fatigue and lack of energy was recently conducted in breast cancer patients before and after breast cancer surgeries [54]. It was observed that patients carrying the homozygous rare variants of $I L 1 B$ (rs16944) and IL10 (rs3024496) had increased and decreased odds of belonging to the higher fatigue class respectively. Furthermore, patients heterozygous or homozygous for ILIRI (rs2110726) rare variants had decreased odds of belonging to the "lower energy" group. To this point, the results of the 
association between $I L 1 B$ (rs16944) and the development of fatigue remain contradictory where a study [54] reported increased while the other [59] reported decreased likelihood of belonging to the fatigued group in patients carrying the rare variant allele while two other studies reported no significant association $[60,61]$.

\section{Neurotransmitter genes and fatigue and energy}

An earlier study [63] has revealed an association between catechol-O-methyltransferase (COMT) gene and the risk for having fatigue in breast cancer patients following breast surgery. Patients with homozygous (Met/Met) or heterozygous (Val/Met) for COMT allele variant (rs4680) had higher fatigue scores when compared with those carrying the wild type (Val/ Val). Although there are many SNPs in the COMT that are worth investigating, this study provides a preliminary data supporting the potential role of genetic variation affecting neurotransmission in predicting fatigue among breast cancer patients.

To further explore the influence of neurotransmitter gene polymorphisms on fatigue and another important symptom (i.e. energy) among breast cancer patients, Eshragh et al. [53] conducted a more comprehensive study to examine some candidate genes involved in the metabolism of many anticancer drugs, neurotransmission and transport of molecules through cell membranes. It was observed that the presence of the following genotypes was associated with lower odds of having more fatigue: homozygous $\mathrm{AA}$ for ADRB2 (rs1042718), heterozygous $(\mathrm{G} / \mathrm{A})$ or homozygous $(\mathrm{A} / \mathrm{A})$ for $B D N F$ (rs6265), heterozygous $(\mathrm{T} / \mathrm{C})$ or homozygous $(\mathrm{C} / \mathrm{C})$ for COMT (rs9332377), heterozygous $(\mathrm{C} / \mathrm{T})$ or homozygous $(\mathrm{T} / \mathrm{T})$ for CYP3A4 (rs4646437), heterozygous (T/C) or homozygous $\mathrm{C} / \mathrm{C}$ for $G C H 1$ (rs3783642), homozygous (C/C) for NOS1 (rs9658498), and heterozygous LA or homozygous LA for $5 H T T L P R$ (rs25531). On the other hand, the presence of the following genotypes was associated with higher odds of being classified in the high fatigue group: homozygous $(\mathrm{C} / \mathrm{C})$ for GALR1 (rs949060), homozygous (T/T) for NOS1 (rs2293052), NPY1R HapA04 (rs9764, rs7687423, and homozygous (A/A) for SLC6A2 (rs17841327). Similarly, for the energy level, the presence of the following genotypes was associated with lower odds of being classified in the lower energy group of patients: homozygous (T/T) for NOS1 (rs471871), SLC6A1 HapD01 (rs10514669, rs297138 and rs1062246), heterozygous $(\mathrm{A} / \mathrm{G})$ for SLC6A2 (rs36027), and homozygous (A/A) for SLC6A4 (rs2020942). On the other hand, the presence of the following genotypes was associated with higher odds of belonging to the lower energy class: heterozygous $(\mathrm{T} / \mathrm{C})$ or homozygous $(\mathrm{C} / \mathrm{C})$ for SLC6A1 (rs2675163), homozygous (A/A) for SLC6A3 (rs37022) and homozygous $(\mathrm{G} / \mathrm{G})$ for TAC1 (rs2072100). In another previous study [58] a significant difference was observed in gene expression between breast cancer patients who had low and high fatigue levels. It is plausible that polymorphisms may affect the gene expression regulating the neurotransmitter system, inflammatory pathways and energy metabolism leading to increased susceptibility to fatigue and low energy levels.
The findings in the above study are very interesting because they have uncovered a significant number of neurotransmitter genes, a gene encoding for the drug metabolizing enzyme (CYP3A4) as well as genes regulating the transport of molecules across cell membrane that could serve as genetic markers of increased susceptibility to high fatigue and low energy in breast cancer patients after surgery. While polymorphisms in COMT and SLC6A4 have been previously linked with fatigue $[63,64]$, other SNPs and/or haplotypes in ADRB2, BDNF, CYP3A4, GALR1, GCH1, NPY1R HapA04, SLC6A1, SLC6A2, SLC6A3, NOS1 and TAC1 are being linked to fatigue or energy or both for the first time in breast cancer patients [53]. Of note is the presence of the three genes (NOS1, $S L C 6 A 2$ and SLC6A4) that were associated with both fatigue and energy, thus further strengthening the hypothesis that fatigue and energy level though commonly grouped together are distinct symptoms. Additional studies are needed to confirm the reproducibility of the role of these SNPs as potential genetic markers of increased susceptibility to fatigue and low energy in breast cancer patients as well as other cancer types.

\section{Psychological Distress}

Mood disturbances are common side effects related to breast cancer diagnosis and treatment and since they may sometimes persist for years after treatment [3], they significantly affect the QOL of breast cancer patients. Recent studies have suggested that inflammatory pathways are involved in a variety of depressive disorders [65-70].

A recent report suggested an association between depression and cytokines gene polymorphisms in breast cancer patients [71]. In particular, patients homozygous for $I L 1 B-511 \mathrm{~T} / \mathrm{T}$ had increased risk for depression both at baseline and after one year follow up. This observation is in agreement with two previous studies also conducted in patients with chronic diseases such as Alzheimer's disease [72] and schizophrenia [73], though a contrary report also exists with regards to the association between $I L 1 B-511 \mathrm{C} / \mathrm{T}$ genetic polymorphism and risk of Alzheimer's disease [74].

The roles of pro-inflammatory cytokines genetic polymorphisms in developing breast cancer-associated depression was further provided by Bower et al. who established that breast cancer patients with heterozygous GG genotype of IL6-174 SNP experienced higher depressive symptoms when compared with those carrying the GC and CC genotypes [61]. Another similar study [75] reported that breast cancer patients who were homozygous for a rare allele variant of TNF- $\alpha$ (rs1799964) had lower odds of developing subsyndromal depression. The study also demonstrated that SNPs in Interferon Gamma Receptor 1 (IFNGR1, rs9376268) and IL6 (rs2069840) were associated with the development of subsyndromal depressive symptoms. Nevertheless, in contrast to the findings by $\mathrm{Kim}$ et al. [71] which demonstrated a significant association between $I L 1 B$ and depression, similar findings could not be confirmed by Saad et al. [75]. Furthermore, the associations between SNPs in cytokines and 
depression appeared to vary depending on the cancer type; for instance, Duun et al. [76] reported an association between two TNF- $\alpha$ SNPs (rs2229074, rs1800629) and depression in patients with various types of cancer (breast, prostate, lung and brain) and their family care givers. On the contrary, similar association was not demonstrable in a cohort of breast cancer patients $[71,75]$. Owing to the complex nature of cancer related depression with multiple genetic factors implicated, additional larger multi-centre studies involving different ethnicities and targeting multiple SNPs may reveal the actual combined effects of the genes [71].

Recent data also suggest that an individual's genetics play an important role in the development of anxiety disorders [77-80]. Additionally, the link between the development of anxiety and inflammatory signalling pathways has also been established [69,81].

Consistent with the findings of Saad et al. on the association between TNF- $\alpha$ (rs1799964) and the development of subsyndromal depression [75], a corresponding decreased odds of higher anxiety class was also observed with the SNP (rs1799964) among breast cancer patients undergoing breast surgery [82]. On the other hand, this study also observed that $T N F-\alpha$ (rs3093662) was associated with higher odds of developing anxiety therefore suggesting that $T N F-\alpha$ SNPs may serve as important predictive marker of increased susceptibility to psychological distress among breast cancer patients.

\section{Memory and Cognitive Function}

Memory impairment is one of the main complaints by patients with breast cancer [83-85] and has been linked to inflammatory processes [86,87]. It was demonstrated that breast cancer patients harbouring the IL6-174 GG and TNF-308 GG genotypes had near significant worse memory complaints [61]. This study therefore suggests that genetic polymorphisms in inflammatory cytokines may contribute to memory impairment among breast cancer patients. However, further studies are required to establish the role of cytokine genes in behavioural changes at both initial stages of breast cancer diagnosis and along the course of treatment; since inflammatory cytokines may also be influenced by surgery, chemotherapy and radiotherapy.

It is well established that breast cancer survivors experience impaired cognitive function which is often associated with cancer treatment [88-90]. The effect of genetic variation on cognitive function of breast cancer survivors was earlier reported by Ahles et al. [91]. The study revealed that breast cancer and lymphoma patients (treated with chemotherapy) who carry at least one allele for apolipoprotein E $\varepsilon 4(A P O E \varepsilon 4)$ gene were more likely to have deficits in cognitive function compared to those who do not harbour the allele. Although the sample size in this study was relatively small (breast cancer $(n=51)$, lymphoma $(n=29)$, Hodgkin's $(n=10)$ and nonHodgkin's lymphomas $(n=19))$ and included patients with lymphomas, it supports the hypothesis that genetic factors could predispose cancer patients to a diminished cognitive function. Subsequently, a more comprehensive study was carried out by Small et al. [92] to examine the impact of COMT polymorphisms on the cognitive function of breast cancer patients. They reported that patients treated with chemotherapy and carry the COMT-Met (Met/Met) genotype were more likely to have a better cognitive function compared to those carrying the Val/Met or Val/Val genotypes. These findings and those of Ahles et al. on APOE \&4 [91] could potentially contribute in future personalized therapy of deficits in cognitive function that are associated with breast cancer chemotherapy.

\section{Sleep Disturbance}

Sleep disturbance is a common but often an unidentified complaint in patients with a variety of cancer diseases [93-95] and particularly among breast cancer women [27,96-98] which can adversely affect patients' QOL [99,100]. Recent studies have suggested an association between cytokine genes and sleep disturbance in oncology patients with several types of cancer (such as breast, prostate, lung or brain) and their family caregivers $[62,101,102]$. However, these findings could not be replicated in a later report which evaluated the association among breast cancer patients only [61]. In contrast, a subsequent similar study on breast cancer patients by Miaskowski et al. [103] demonstrated that NFKB2 (rs1056890) carriers had decreased odds of being classified in the high sustained sleep disturbance class, while carriers of the IL13 (rs1800925) SNP IL1R2 HapA2 haplotype (rs11674595, rs7570441) had increased odds of having a high sustained sleep disturbance. The fact that no association could be established between IL13 and sleep disturbance among oncology patients and their family care givers [102] warrants additional multi-centre studies to delineate the specific role of cytokines in predicting sleep disturbance among cancer patients including breast cancer.

\section{Pain}

Acute and chronic pains constitute a major complaint associated with breast cancer and its treatment [104-107]. A number of factors may be responsible for breast pain in breast cancer patients. Prior to surgery, breast pain may result from the release of pain mediators by the tumour or inflammatory changes in the breast tissue (following tissue biopsy) which is mainly mediated by pro-inflammatory cytokines [108-111]. On the other hand, post-operative pain in breast cancer patients may arise from or be associated with nerve injury that may occur during surgery or following radiotherapy [104,112,113]. Persistent pain is associated with significant impairment of quality of life [28,114-116].

\section{Cytokine genes and pain}

McCann et al. [117] documented for the first time that cytokine genes are associated with the development of breast pain prior to surgery (preoperatively). They reported that carriers of IL1R1 (rs2110726) had reduced odds of having breast pain before surgery while carriers of IL13 (rs1295686) had higher 
odds of having breast pain prior to surgery. A similar study conducted among breast cancer women following surgery (postoperatively) [118] demonstrated that carriers of IL1R2 (rs11674595) had higher odds of developing a severe persistent breast pain while those harbouring the IL10 haplotype A8 (made up of seven SNPs i.e. rs3024505, rs3024498, rs3024496, rs1878672, rs1518111, rs1518110, rs3024491) had decreased odds of having severe persistent breast pain. Nevertheless, the role of IL10 haplotype A8 requires further validation since contradictory findings have been reported in terms of its functional significance in other disease conditions [119-122].

\section{Potassium channel genes and pain}

The role of potassium channel genes in predicting the occurrence of both pre- and postoperative breast pain has recently been investigated. In the preoperative pain assessment, it was reported that four potassium channel genes (KCNS1 (rs4499491), KCNJ3 (rs7574878), KCNJ6 (rs2835914, rs8129919, rs2836050) and KCNK9 (rs3780039, rs11166921)) were associated with the occurrence of breast pain prior to breast cancer surgery [123], thus suggesting that variation in potassium channel genes potentially contribute to interindividual variability in developing preoperative breast pain. To further explore the contribution of genetic variation in potassium channel genes on the development of persistent breast pain, Langford et al. [124] also examined the association between potassium channel genes and the development of persistent breast pain in a similar cohort of women with breast cancer following surgery. They reported that KCNA1 (rs4766311), KCND2 (rs1072198), KCNJ3 (rs12995382 and rs17641121), KCNJ6 (rs858003) and KCNK9 (rs2542424 and rs2545457) were associated with persistent breast pain postoperatively. Overall, the findings in breast cancer patients both before and after surgery strongly suggest that potassium channel genes may serve as potential therapeutic targets in the management of persistent pain associated with breast cancer. However, further investigations are warranted in larger samples which should also include functional studies involving the target genes.

\section{Neurotransmitter genes and pain}

At the time of this review, only a single study [63] reported on the influence of neurotransmitter gene polymorphisms on pain in breast cancer patients where patients harbouring the Met/Met or Val/Met genotypes for COMT (rs4680) were more likely to experience greater sensitivity to pain as compared to those carrying the Val/Val genotype. Additional studies are suggested to explore the roles of as many SNPs as possible in the COMT gene as predictors of higher sensitivity to pain in breast cancer patients and other cancer types.

The influence of genetic variation on various symptoms is summarized in Table 1.

Table 1. Summary of SNPs and the affected symptoms.

\begin{tabular}{|c|c|c|c|}
\hline Gene/allele/SNP & Symptoms assessed & Major findings & References \\
\hline IL1B C>T (rs16944) & Fatigue & Increased odds of belonging to non-fatigued group among $\mathrm{T} / \mathrm{T}$ or $\mathrm{C} / \mathrm{T}$ carriers & [59] \\
\hline IL6 G>C (rs1800795) & Fatigue & Increased odds of belonging to the fatigued group among GG or $\mathrm{C} / \mathrm{C}$ carriers & \\
\hline TNF G>A (rs1800629) & Fatigue & G/G carriers had higher fatigue scores & [61] \\
\hline IL6 G>C (rs1800795) & Fatigue & Higher fatigue scores in $\mathrm{G} / \mathrm{G}$ carriers & \\
\hline IL1B G>A (rs16944) & Fatigue & $\begin{array}{l}\text { Increased odds of being classified in the higher fatigue group among } A / A \\
\text { carriers }\end{array}$ & [54] \\
\hline IL10 T>C (rs3024496) & Fatigue & $\begin{array}{l}\text { Decreased odds of being classified in the higher fatigue group among } \mathrm{C} / \mathrm{C} \\
\text { carriers }\end{array}$ & \\
\hline IL1R1 C>T (rs2110726) & Energy levels & $\begin{array}{l}\text { Decreased odds of being classified in the lower energy class among } \mathrm{C} / \mathrm{T} \text { or } \\
\mathrm{T} / \mathrm{T} \text { carriers }\end{array}$ & \\
\hline COMT G>A (rs4680) & Fatigue & higher fatigue scores in Met/Met or Val/Met carriers & [63] \\
\hline$A D R B 2 \mathrm{C}>\mathrm{A}(\mathrm{rs} 1042718)$ & Fatigue & Decreased odds of belonging to higher fatigue class in A/A carriers & {$[53]$} \\
\hline$B D N F \mathrm{G}>\mathrm{A}(\mathrm{rs} 6265)$ & Fatigue & Decreased odds of belonging to higher fatigue class in G/A or $A / A$ carriers & \\
\hline COMT T>C (rs9332377) & Fatigue & Decreased odds of belonging to higher fatigue class in $\mathrm{T} / \mathrm{C}$ or $\mathrm{C} / \mathrm{C}$ carriers & \\
\hline CYP3A4 C>T (rs4646437) & Fatigue & Decreased odds of belonging to higher fatigue class in $\mathrm{C} / \mathrm{T}$ or $\mathrm{T} / \mathrm{T}$ carriers & \\
\hline $\mathrm{GCH} 1 \mathrm{~T}>\mathrm{C}(\mathrm{rs} 3783642)$ & Fatigue & Decreased odds of belonging to higher fatigue class in $\mathrm{T} / \mathrm{C}$ or $\mathrm{C} / \mathrm{C}$ carriers & \\
\hline NOS1 T>C (rs9658498) & Fatigue & Decreased odds of belonging to higher fatigue class $\mathrm{C} / \mathrm{C}$ carriers & \\
\hline $5 H T T L P R+r s 25531$ & Fatigue & $\begin{array}{l}\text { Decreased odds of belonging to higher fatigue class in heterozygous or } \\
\text { homozygous LA carriers }\end{array}$ & \\
\hline
\end{tabular}




\begin{tabular}{|c|c|c|c|}
\hline GALR1 G>C (rs949060) & Fatigue & Increased odds of belonging to higher fatigue class in $\mathrm{C} / \mathrm{C}$ carriers & \\
\hline NOS1 C>T (rs2293052) & Fatigue & Increased odds of belonging to higher fatigue class in $T / T$ carriers & \\
\hline NPY1R HapA04 (rs9764, rs7687423) & Fatigue & Increased odds of belonging to higher fatigue class & \\
\hline SLC6A2 C>A (rs17841327) & Fatigue & Increased odds of belonging to higher fatigue class in A/A carriers & \\
\hline NOS1 A>T (rs471871) & Energy levels & $\begin{array}{l}\text { Decreased odds of being classified in the lower energy group among } T / T \\
\text { carriers }\end{array}$ & \\
\hline $\begin{array}{l}\text { SLC6A1 HapD01 (rs10514669, rs297138 } \\
\text { and rs1062246) }\end{array}$ & Energy levels & Decreased odds of being classified in the lower energy group & \\
\hline$S L C 6 A 2 A>G(r s 36027)$ & Energy levels & $\begin{array}{l}\text { Decreased odds of being classified in the lower energy group among } A / G \\
\text { carriers }\end{array}$ & \\
\hline SLC6A4 G>A (rs2020942) & Energy levels & $\begin{array}{l}\text { Decreased odds of being classified in the lower energy group among } A / G \\
\text { carriers }\end{array}$ & \\
\hline SLC6A1 T>C (rs2675163) & Energy levels & $\begin{array}{l}\text { Increased odds of being classified in the lower energy group among } T / C \text { or } \\
\mathrm{C} / \mathrm{C} \text { carriers }\end{array}$ & \\
\hline SLC6A3 T>A (rs37022) & Energy levels & $\begin{array}{l}\text { Increased odds of being classified in the lower energy group among A/A } \\
\text { carriers }\end{array}$ & \\
\hline TAC1 A>G (rs2072100) & Energy levels & $\begin{array}{l}\text { Increased odds of being classified in the lower energy group among G/G } \\
\text { carriers }\end{array}$ & \\
\hline IL1B-511 C>T (rs16944) & Depression & Increased odds of having depression in $\mathrm{T} / \mathrm{T}$ carriers & {$[71]$} \\
\hline IL6-174 G>C (rs1800795) & Depression & Higher depressive symptoms in G/G carriers & [61] \\
\hline$T N F-\alpha \mathrm{T}>\mathrm{C}(\mathrm{rs} 1799964)$ & Depression & Decreased odds of belonging to subsyndromal depression in $\mathrm{C} / \mathrm{C}$ carriers & {$[75]$} \\
\hline IFNGR1 G>A (rs9376268) & Depression & $\begin{array}{l}\text { Increased odds of belonging to subsyndromal depression in } G / A \text { or } A / A \\
\text { carriers }\end{array}$ & \\
\hline IL6 C>G (rs2069840) & Depression & Increased odds of belonging to subsyndromal depression in G/G carriers & \\
\hline$T N F-\alpha \mathrm{T}>\mathrm{C}(\mathrm{rs} 1799964)$ & Anxiety & Decreased odds of belonging to high anxiety class in $\mathrm{C} / \mathrm{C}$ carriers & {$[82]$} \\
\hline$T N F-\alpha A>G(r s 3093662)$ & Anxiety & Increased odds of belonging to high anxiety class in $A / G$ or $G / G$ carriers & \\
\hline NFKB2 C>T (rs1056890) & Sleep disturbance & $\begin{array}{l}\text { Decreased odds of being classified in the high sustained sleep disturbance } \\
\text { class among } C / T \text { or } T / T \text { carriers }\end{array}$ & [103] \\
\hline IL13 C>T (rs1800925) & Sleep disturbance & $\begin{array}{l}\text { Increased odds of being classified in the high sustained sleep disturbance } \\
\text { class among } \mathrm{C} / \mathrm{T} \text { or } \mathrm{T} / \mathrm{T} \text { carriers }\end{array}$ & \\
\hline IL1R2 HapA2 (rs11674595, rs7570441) & Sleep disturbance & $\begin{array}{l}\text { Increased odds of being classified in the high sustained sleep disturbance } \\
\text { class }\end{array}$ & \\
\hline IL1R1 C>T (rs2110726) & Pain & Decreased odds of reporting breast pain in $\mathrm{C} / \mathrm{T}$ and $\mathrm{T} / \mathrm{T}$ carriers & [117] \\
\hline IL13 G>A (rs1295686) & Pain & Increased odds of reporting breast pain in G/A or A/A carriers & \\
\hline IL1R2 T>C (rs11674595) & Pain & Increased odds of being classified in the severe pain class in $\mathrm{C} / \mathrm{C}$ carriers & [118] \\
\hline IL10 haplotype $\mathrm{A} 8$ & Pain & Decreased odds of being classified in the severe pain class in $\mathrm{C} / \mathrm{C}$ carriers & \\
\hline KCNS1 C>A (rs4499491) & Pain & Increased odds of reporting preoperative breast pain in A/A carriers & [123] \\
\hline KCNJ3 T>G (rs7574878) & Pain & Decreased odds of reporting preoperative breast pain in $T / G$ or $G / G$ carriers & \\
\hline KCNJ6 G>C (rs2835914) & Pain & Decreased odds of reporting preoperative breast pain in $\mathrm{G} / \mathrm{C}$ or $\mathrm{C} / \mathrm{C}$ carriers & \\
\hline KCNJ6 G>A (rs8129919) & Pain & $\begin{array}{l}\text { Increased odds of reporting preoperative breast pain in patient carrying each } \\
\text { dose of the rare A allele }\end{array}$ & \\
\hline KCNJ6 C>T (rs2836050) & Pain & Increased odds of reporting preoperative breast pain in $\mathrm{T} / \mathrm{T}$ carriers & \\
\hline KCNK9 T>G (rs3780039) & Pain & Increased odds of reporting preoperative breast pain in $T / G$ or $G / G$ carriers & \\
\hline KCNK9 C>A (rs11166921) & Pain & Increased odds of reporting preoperative breast pain in $\mathrm{A} / \mathrm{A}$ carriers & \\
\hline
\end{tabular}




\begin{tabular}{|c|c|c|c|}
\hline KCNA1 C>T (rs4766311) & Pain & $\begin{array}{l}\text { Decreased odds of belonging to the mild pain class in patients carrying each } \\
\text { dose of T allele }\end{array}$ & [124] \\
\hline KCND2 A>G (rs1072198) & Pain & Increased odds of belonging to the mild pain class in $A / G$ or $G / G$ carriers & \\
\hline KCNJ3 T>C (rs12995382) & Pain & Decreased odds of belonging to the mild pain class in $\mathrm{T} / \mathrm{C}$ or $\mathrm{C} / \mathrm{C}$ carriers & \\
\hline KCNJ3 T>C (rs17641121) & Pain & Increased odds of belonging to the mild pain class in $\mathrm{C} / \mathrm{C}$ carriers & \\
\hline KCNJ6 C>T (rs858003) & Pain & Increased odds of belonging to the mild pain class in $\mathrm{T} / \mathrm{T}$ carriers & \\
\hline KCNK9 A>G (rs2542424) & Pain & Decreased odds of belonging to the mild pain class in $A / G$ or $G / G$ carriers & \\
\hline KCNK9 T>C (rs2545457) & Pain & Increased odds of belonging to the mild pain class in $T / C$ or $C / C$ carriers & \\
\hline COMT G>A (rs4680) & Pain & Increased odds of pain sensitivity in Met/Met or Val/Met carriers & [63] \\
\hline$A P O E \varepsilon 4$ & Cognitive function & $\begin{array}{l}\text { Increased likelihood of having impaired cognitive function in carriers of at } \\
\text { least one } A P O E \& 4 \text { allele }\end{array}$ & [91] \\
\hline COMT G>A (rs4680) & Cognitive function & $\begin{array}{l}\text { Increased likelihood of having better cognitive function in carriers of Met/Met } \\
\text { genotype }\end{array}$ & [92] \\
\hline
\end{tabular}

\section{Genetic Polymorphisms and Symptom Cluster}

It could be deduced from the above discussion that genetic variations in the cytokine genes influence a number of commonly encountered symptoms in breast cancer patients which include fatigue, psychological distress (depression and anxiety), pain, sleep disturbance and memory impairment all of which are associated with inflammatory cytokines. In the era of personalized medicine, identification of molecular markers that can predict patients at risk of developing these debilitating complaints in the form of symptom cluster is important. Recent evidences support the fact that fatigue, depression, pain and sleep disturbances share some common pathways that make them a symptom cluster $[7,125,126]$.

The findings from two recent studies which evaluated the influence of genetic variation on symptoms cluster in oncology patients and their family care givers [127]; specifically among breast cancer patients [128] have revealed promising results that could pave way for establishing the link between genetic markers and symptom cluster. In a later study [128], it was demonstrated that breast cancer patients who were homozygous for the rare allele $(\mathrm{G} / \mathrm{G})$ of IL6 (rs2069845), heterozygous $(\mathrm{G} / \mathrm{A})$ or homozygous (A/A) for IL13 (rs1295686) as well as heterozygous $(\mathrm{C} / \mathrm{T})$ or homozygous (T/T) for TNF- $\alpha$ (rs1800610) had higher odds of being categorized in the all high symptom class (i.e. those who reported high levels of fatigue, pain, depression and sleep disturbances).

Although the IL6 (rs2069845) is reported to be associated with the symptom cluster for the first time in this study, other SNPs in the IL6 have been previously reported to be associated with fatigue [61] and depression [61,75]. For the IL13 (rs1295686), contradictory results exist in a different cohort of oncology patients and their family caregivers [127] where no association was established with the symptom cluster. Notwithstanding, the IL13 (rs1295686) was reported to be associated with breast pain before surgery [117]. For the $T N F-\alpha$ (rs1800610), no study has previously reported its association with any of these symptoms, although another SNP in the TNF- $\alpha$ (rs1800629) was shown to be associated with fatigue in breast cancer patients (61) and depression in oncology patients and their family caregivers [76]. The association of this SNP with depression was however not reproducible in breast cancer patients $[71,75]$. The inconsistency may warrant further investigations to define common molecular pathways underlining the symptom cluster of fatigue, pain, depression and sleep disturbance which in turn can be used for the development of targeted interventions for symptom cluster based on genetic markers.

Nevertheless, sine the majority of the studies were conducted in a homogenous breast cancer cohort at different clinical stages, it will be interesting to determine if these findings can be replicated in women diagnosed with breast cancer from various racial, ethnic and socio-economic status. It is also important to conduct larger multicentre studies that consider a control group (where applicable) of women without prior history of breast cancer so as to determine whether the SNPs are primarily specific to breast cancer or they also play a similar role in apparently healthy population.

\section{Conclusions}

The impact of genetic polymorphism on patient-reported symptoms that are associated with QOL impairment vary depending on the cancer types. Certain gene polymorphisms exert an opposing influence with respect to the risk of some breast cancer symptoms. For instance COMT (Met/Met) genotype was associated with better cognitive function in one study while in another study; it was associated with higher fatigue and pain scores in breast cancer patients. Consequently, when evaluating patients for personalized treatment in future, this variation may be important in ensuring maximum benefit for patients.

Although the vast majority of the SNPs reported in the reviewed literature are yet to be fully validated for integration in to clinical practice or clinical drug development, the SNPs in 
the cytokines genes appear to be promising. Additional functional studies are therefore needed to establish whether the presence of polymorphisms is associated with correspondingly altered functions based on the different alleles. A thorough understanding of the underlying molecular mechanisms mediating the development of the various symptoms might help in detection of at-risk patients and designing of novel therapeutic interventions. When validated, the different genotypes could serve as genetic predictors of poor QOL and may also be useful in the development of targeted therapy and designing of non-pharmacologic interventions to ameliorate the debilitating impairment of QOL in breast cancer patients.

\section{Acknowledgements}

This work was supported by grant No. 1001/PPSP/853005 from Universiti Sains Malaysia (USM). The authors wish to acknowledge the Tertiary Education Trust Fund (TETFund) awarded to the first author.

\section{Conflicts of Interest}

The authors declare no conflicts of interest.

\section{References}

1. Ferlay J, Soerjomataram I, Dikshit R, Eser S, Mathers C, Rebelo M. Cancer incidence and mortality worldwide: sources, methods and major patterns in GLOBOCAN 2012. Int J Cancer 2015; 136: 359-386.

2. Siegel R, Ma J, Zou Z, Jemal A. Cancer statistics, 2014. CA Cancer J Clin 2014; 64: 9-29.

3. Bower JE. Behavioral symptoms in patients with breast cancer and survivors. J Clin Oncol 2008; 26: 768-777.

4. Gold M, Dunn LB, Phoenix B, Paul SM, Hamolsky D, Levine JD. Co-occurrence of anxiety and depressive symptoms following breast cancer surgery and its impact on quality of life. Off J Eur Oncol Nurs Soci 2016; 20: 97-105.

5. Janz NK, Mujahid M, Chung LK, Lantz PM, Hawley ST, Morrow M. Symptom experience and quality of life of women following breast cancer treatment. J Womens Health (Larchmt) 2007; 16: 1348-1361.

6. Meeske K, Smith AW, Alfano CM, McGregor BA, McTiernan A, Baumgartner KB. Fatigue in breast cancer survivors two to five years post diagnosis: a HEAL Study report. Qual Life Res 2007; 16: 947-960.

7. Barsevick AM. The elusive concept of the symptom cluster. Oncol Nurs Forum 2007; 34: 971-980.

8. Kim HJ, Barsevick AM, Beck SL, Dudley W. Clinical subgroups of a psychoneurologic symptom cluster in women receiving treatment for breast cancer: a secondary analysis. Oncol Nurs Forum 2012; 39: 20-30.

9. Miaskowski C. Future directions in symptom cluster research. Semin Oncol Nurs 2016; 32: 405-415.

10. Miaskowski C, Cooper BA, Paul SM, Dodd M, Lee K, Aouizerat BE. Subgroups of patients with cancer with different symptom experiences and quality-of-life outcomes: a cluster analysis. Oncol Nurs Forum 2006; 33: 79-89.

11. Choi S, Ryu E. Effects of symptom clusters and depression on the quality of life in patients with advanced lung cancer. Eur J Cancer Care (Engl) 2016.

12. Pud D, Ben Ami S, Cooper BA, Aouizerat BE, Cohen D, Radiano R. The symptom experience of oncology outpatients has a different impact on quality-of-life outcomes. J Pain Symptom Manage 2008; 35: 162-170.

13. Trask PC, Hsu MA, McQuellon R. Other paradigms: health-related quality of life as a measure in cancer treatment: its importance and relevance. Cancer J 2009; 15: 435-440.

14. Dormer L. Quality of life in cancer clinical trials: researchers, patients and policy makers. Expert Rev Pharmacoecon Outcomes Res 2011; 11: 661-665.

15. Kaluri R, Reddy CP. A framework for sign gesture recognition using improved genetic algorithm and adaptive filter. Cogent Eng 2016; 3: 1251730.

16. Kaluri R, Reddy P. Sign gesture recognition using modified region growing algorithm and adaptive genetic fuzzy classifier. Int J Intell Eng Syst 2016; 9: 225-233.

17. Paraskevi T. Quality of life outcomes in patients with breast cancer. Oncol Rev 2012; 6: 2.

18. Montazeri A. Health-related quality of life in breast cancer patients: a bibliographic review of the literature from 1974 to 2007. J Exp Clin Cancer Res 2008; 27: 32.

19. Andrykowski MA, Donovan KA, Jacobsen PB. Magnitude and correlates of response shift in fatigue ratings in women undergoing adjuvant therapy for breast cancer. J Pain Symptom Manage 2009; 37: 341-351.

20. Browall M, Ahlberg K, Karlsson P, Danielson E, Persson LO, Gaston-Johansson F. Health-related quality of life during adjuvant treatment for breast cancer among postmenopausal women. Off J Eur Oncol Nurs Soc 2008; 12: $180-189$

21. Donovan KA, Small BJ, Andrykowski MA, Munster P, Jacobsen PB. Utility of a cognitive-behavioral model to predict fatigue following breast cancer treatment. Health Psychol 2007; 26: 464-472.

22. Mehnert A, Scherwath A, Schirmer L, Schleimer B, Petersen C, Schulz-Kindermann F. The association between neuropsychological impairment, self-perceived cognitive deficits, fatigue and health related quality of life in breast cancer survivors following standard adjuvant versus high-dose chemotherapy. Patient Educ Couns 2007; 66: 108-118.

23. Wang Y, Zhu X, Li L, Yi J, He J. What factors affect the insomnia symptom trajectories in women with nonmetastatic breast cancer? J Pain Sympt Manag 2016; 52: $850-858$.

24. Nes RB, Roysamb E, Tambs K, Harris JR, ReichbornKjennerud T. Subjective well-being: genetic and environmental contributions to stability and change. Psychol Med 2006; 36: 1033-1042. 
25. Haworth CM, Nelson SK, Layous K, Carter K, Jacobs Bao K, Lyubomirsky S. Stability and change in genetic and environmental influences on well-being in response to an intervention. PLoS One 2016; 11: 0155538.

26. Romeis JC, Heath AC, Xian H, Eisen SA, Scherrer JF, Pedersen NL. Heritability of SF-36 among middle-age, middle-class, male-male twins. Med Care 2005; 43: 1147-1154.

27. Savard J, Ivers H, Villa J, Caplette-Gingras A, Morin CM. Natural course of insomnia comorbid with cancer: an 18month longitudinal study. J Clin Oncol 2011; 29: 3580-3586.

28. Beyaz SG, Ergonenc JS, Ergonenc T, Sonmez OU, Erkorkmaz U, Altintoprak F. Postmastectomy pain: a cross-sectional study of prevalence, pain characteristics, and effects on quality of life. Chin Med J (Engl) 2016; 129: 66-71.

29. Dodd MJ, Cho MH, Cooper BA, Petersen J, Bank KA, Lee KA. Identification of latent classes in patients who are receiving biotherapy based on symptom experience and its effect on functional status and quality of life. Oncol Nurs Forum 2011; 38: 33-42.

30. Esther Kim JE, Dodd MJ, Aouizerat BE, Jahan T, Miaskowski C. A review of the prevalence and impact of multiple symptoms in oncology patients. J Pain Symptom Manage 2009; 37: 715-736.

31. Sprangers MA, Sloan JA, Veenhoven R, Cleeland CS, Halyard MY, Abertnethy AP. The establishment of the GENEQOL consortium to investigate the genetic disposition of patient-reported quality-of-life outcomes. Twin Res Hum Genet 2009; 12: 301-311.

32. Rausch SM, Clark MM, Patten C, Liu H, Felten S, Li Y. Relationship between cytokine gene single nucleotide polymorphisms and symptom burden and quality of life in lung cancer survivors. Cancer 2010; 116: 4103-4113.

33. Rausch SM, Gonzalez BD, Clark MM, Patten C, Felten S, Liu H. SNPs in PTGS2 and LTA predict pain and quality of life in long term lung cancer survivors. Lung Cancer 2012; 77: 217-223.

34. Alexander K, Cooper B, Paul SM, West C, Yates P, Kober KM. Evidence of associations between cytokine gene polymorphisms and quality of life in patients with cancer and their family caregivers. Oncol Nurs Forum 2014; 41: 267-281.

35. Alexander KE, Cooper BA, Paul SM, Yates P, Aouizerat BE, Miaskowski C. Phenotypic and molecular characteristics associated with various domains of quality of life in oncology patients and their family caregivers. Qual Life Res 2016; 25: 2853-2868.

36. Louati K, Berenbaum F. Fatigue in chronic inflammationa link to pain pathways. Arthritis Res Ther 2015; 17: 254.

37. Miller AH, Ancoli-Israel S, Bower JE, Capuron L, Irwin MR. Neuroendocrine-immune mechanisms of behavioral comorbidities in patients with cancer. J Clin Oncol 2008; 26: 971-982.
38. Bower JE, Ganz PA, Aziz N, Fahey JL. Fatigue and proinflammatory cytokine activity in breast cancer survivors. Psychosom Med 2002; 64: 604-611.

39. Bower JE, Ganz PA, Aziz N, Fahey JL, Cole SW. T-cell homeostasis in breast cancer survivors with persistent fatigue. J Natl Cancer Inst 2003; 95: 1165-1168.

40. Bower JE, Ganz PA, Irwin MR, Arevalo JM, Cole SW. Fatigue and gene expression in human leukocytes: increased NF-kappaB and decreased glucocorticoid signaling in breast cancer survivors with persistent fatigue. Brain Behav Immun 2011; 25: 147-150.

41. Collado-Hidalgo A, Bower JE, Ganz PA, Cole SW, Irwin MR. Inflammatory biomarkers for persistent fatigue in breast cancer survivors. Clin Cancer Res 2006; 12: 2759-2766

42. Bower JE, Ganz PA, Tao ML, Hu W, Belin TR, Sepah S. Inflammatory biomarkers and fatigue during radiation therapy for breast and prostate cancer. Clin Cancer Res 2009; 15: 5534-5540.

43. Orre IJ, Reinertsen KV, Aukrust P, Dahl AA, Fossa SD, Ueland T. Higher levels of fatigue are associated with higher CRP levels in disease-free breast cancer survivors. J Psychosom Res 2011; 71: 136-141.

44. Markkula A, Simonsson M, Ingvar C, Rose C, Jernstrom H. IL6 genotype, tumour ER-status, and treatment predicted disease-free survival in a prospective breast cancer cohort. BMC Cancer 2014; 14: 759.

45. DeMichele A, Gray R, Horn M, Chen J, Aplenc R, Vaughan WP. Host genetic variants in the interleukin-6 promoter predict poor outcome in patients with estrogen receptor-positive, node-positive breast cancer. Cancer Res 2009; 69: 4184-4191.

46. Hefler LA, Grimm C, Lantzsch T, Lampe D, Leodolter S, Koelbl H. Interleukin-1 and interleukin-6 gene polymorphisms and the risk of breast cancer in caucasian women. Clin Cancer Res. 2005; 11: 5718-5721.

47. Fang F, Yao L, Yu XJ, Yu L, Wu Q, Yu L. TNFalpha -308 $\mathrm{G} / \mathrm{A}$ polymorphism is associated with breast cancer risk: a meta-analysis involving 10,184 cases and 12,911 controls. Breast Cancer Res Treat 2010; 122: 267-271.

48. Pooja S, Chaudhary P, Nayak LV, Rajender S, Saini KS, Deol D. Polymorphic variations in IL-1beta, IL-6 and IL-10 genes, their circulating serum levels and breast cancer risk in Indian women. Cytokine 2012; 60: 122-128.

49. Andreassen $\mathrm{CN}$, Alsner J, Overgaard J, Herskind C, Haviland J, Owen R. TGFB1 polymorphisms are associated with risk of late normal tissue complications in the breast after radiotherapy for early breast cancer. Radiother Oncol 2005; 75: 18-21.

50. Reuther S, Szymczak S, Raabe A, Borgmann K, Ziegler A, Petersen C. Association between SNPs in defined functional pathways and risk of early or late toxicity as well as individual radiosensitivity. Strahlenther Onkol 2015; 191: 59-66.

51. Van Onselen C, Aouizerat BE, Dunn LB, Paul SM, West C, Hamolsky D. Differences in sleep disturbance, fatigue 
and energy levels between women with and without breast pain prior to breast cancer surgery. Breast 2013; 22: 273-276.

52. Aouizerat BE, Dhruva A, Paul SM, Cooper BA, Kober KM, Miaskowski C. Phenotypic and molecular evidence suggests that decrements in morning and evening energy are distinct but related symptoms. J Pain Symptom Manage 2015; 50: 599-614.

53. Eshragh J, Dhruva A, Paul SM, Cooper BA, Mastick J, Hamolsky D. Associations between neurotransmitter genes and fatigue and energy levels in women following breast cancer surgery. J Pain Symptom Manage 2017; 53: 67-84.

54. Kober KM, Smoot B, Paul SM, Cooper BA, Levine JD, Miaskowski C. Polymorphisms in cytokine genes are associated with higher levels of fatigue and lower levels of energy in women after breast cancer surgery. J Pain Symptom Manage 2016; 52: 695-708.

55. Meeusen R, Roelands B. Central fatigue and neurotransmitters, can thermoregulation be manipulated? Scand J Med Sci Sports 2010; 20: 19-28.

56. Meeusen $\mathrm{R}$, Watson $\mathrm{P}$, Hasegawa $\mathrm{H}$, Roelands $\mathrm{B}$, Piacentini MF. Brain neurotransmitters in fatigue and overtraining. Appl Physiol Nutr Metab 2007; 32: 857-864.

57. Saligan LN, Olson K, Filler K, Larkin D, Cramp F, Yennurajalingam $\mathrm{S}$. The biology of cancer-related fatigue: a review of the literature. Support Care Cancer 2015; 23: 2461-2478.

58. Kober KM, Dunn L, Mastick J, Cooper B, Langford D, Melisko M. Gene expression profiling of evening fatigue in women undergoing chemotherapy for breast cancer. Biol Res Nurs 2016; 18: 370-385.

59. Collado-Hidalgo A, Bower JE, Ganz PA, Irwin MR, Cole SW. Cytokine gene polymorphisms and fatigue in breast cancer survivors: early findings. Brain Behav Immun 2008; 22: 1197-1200.

60. Reinertsen KV, Grenaker Alnaes GI, Landmark-Hoyvik H, Loge JH, Wist E, Kristensen VN. Fatigued breast cancer survivors and gene polymorphisms in the inflammatory pathway. Brain Behav Immun 2011; 25: 1376-1383.

61. Bower JE, Ganz PA, Irwin MR, Castellon S, Arevalo J, Cole SW. Cytokine genetic variations and fatigue among patients with breast cancer. J Clin Oncol 2013; 31: 1656-1661.

62. Aouizerat BE, Dodd M, Lee K, West C, Paul SM, Cooper BA. Preliminary evidence of a genetic association between tumor necrosis factor alpha and the severity of sleep disturbance and morning fatigue. Biol Res Nurs 2009; 11: 27-41.

63. Fernandez-de-las-Penas C, Fernandez-Lao C, CantareroVillanueva I, Ambite-Quesada S, Rivas-Martinez I, del Moral-Avila R. Catechol-O-methyltransferase genotype (Val158met) modulates cancer-related fatigue and pain sensitivity in breast cancer survivors. Breast Cancer Res Treat 2012; 133: 405-412.
64. Narita M, Nishigami N, Narita N, Yamaguti K, Okado N, Watanabe Y. Association between serotonin transporter gene polymorphism and chronic fatigue syndrome. Biochem Biophys Res Commun 2003; 311: 264-266.

65. Belzeaux R, Formisano-Treziny C, Loundou A, Boyer L, Gabert J, Samuelian JC. Clinical variations modulate patterns of gene expression and define blood biomarkers in major depression. J Psychiatr Res 2010; 44: 1205-1213.

66. Uddin M, Koenen KC, Aiello AE, Wildman DE, de los Santos R, Galea S. Epigenetic and inflammatory marker profiles associated with depression in a community-based epidemiologic sample. Psychol Med 2011; 41: 997-1007.

67. Valkanova V, Ebmeier KP, Allan CL. CRP, IL-6 and depression: a systematic review and meta-analysis of longitudinal studies. J Affect Disord 2013; 150: 736-744.

68. Maes M, Yirmyia R, Noraberg J, Brene S, Hibbeln J, Perini G. The inflammatory \& neurodegenerative (I\&ND) hypothesis of depression: leads for future research and new drug developments in depression. Metab Brain Dis 2009; 24: 27-53.

69. Miller AH, Haroon E, Raison CL, Felger JC. Cytokine targets in the brain: impact on neurotransmitters and neurocircuits. Depress Anxiety 2013; 30: 297-306.

70. Miller AH, Raison CL. The role of inflammation in depression: from evolutionary imperative to modern treatment target. Nat Rev Immunol 2016; 16: 22-34.

71. Kim JM, Stewart R, Kim SY, Kang HJ, Jang JE, Kim SW. A one year longitudinal study of cytokine genes and depression in breast cancer. J Affect Disord 2013; 148: 57-65.

72. McCulley MC, Day IN, Holmes C. Association between interleukin 1-beta promoter (-511) polymorphism and depressive symptoms in Alzheimers disease. Am J Med Genet B Neuropsychiatr Genet 2004; 124: 50-53.

73. Rosa A, Peralta V, Papiol S, Cuesta MJ, Serrano F, Martinez-Larrea A. Interleukin-1beta (IL-1beta) gene and increased risk for the depressive symptom-dimension in schizophrenia spectrum disorders. Am J Med Genet B Neuropsychiatr Genet 2004; 124: 10-14.

74. Ravaglia G, Paola F, Maioli F, Martelli M, Montesi F, Bastagli L. Interleukin-1beta and interleukin-6 gene polymorphisms as risk factors for $\mathrm{AD}$ : a prospective study. Exp Gerontol 2006; 41: 85-92.

75. Saad S, Dunn LB, Koetters T, Dhruva A, Langford DJ, Merriman JD. Cytokine gene variations associated with subsyndromal depressive symptoms in patients with breast cancer. Off J Eur Oncol Nurs Soc 2014; 18: 397-404.

76. Dunn LB, Aouizerat BE, Langford DJ, Cooper BA, Dhruva A, Cataldo JK. Cytokine gene variation is associated with depressive symptom trajectories in oncology patients and family caregivers. Off J Eur Oncol Nurs Soc 2013; 17: 346-353.

77. Webb BT, Guo AY, Maher BS, Zhao Z, van den Oord EJ, Kendler KS. Meta-analyses of genome-wide linkage scans 
of anxiety-related phenotypes. Eur J Hum Genet 2012; 20: 1078-1084.

78. Shimada-Sugimoto M, Otowa T, Hettema JM. Genetics of anxiety disorders: Genetic epidemiological and molecular studies in humans. Psychiatry Clin Neurosci 2015; 69: 388-401.

79. McGrath LM, Weill S, Robinson EB, Macrae R, Smoller JW. Bringing a developmental perspective to anxiety genetics. Dev Psychopathol 2012; 24: 1179-1193.

80. Sokolowska E, Hovatta I. Anxiety genetics-findings from cross-species genome-wide approaches. Biol Mood Anxiety Disord 2013; 3: 9.

81. Hou R, Baldwin DS. A neuroimmunological perspective on anxiety disorders. Hum Psychopharmacol 2012; 27: 6-14.

82. Miaskowski C, Elboim C, Paul SM, Mastick J, Cooper BA, Levine JD. Polymorphisms in tumor necrosis factoralpha are associated with higher anxiety levels in women after breast cancer surgery. Clin Breast Cancer 2016; 16: 63-71.

83. Fan HG, Houede-Tchen N, Yi QL, Chemerynsky I, Downie FP, Sabate K. Fatigue, menopausal symptoms, and cognitive function in women after adjuvant chemotherapy for breast cancer: 1- and 2-year follow-up of a prospective controlled study. J Clin Oncol 2005; 23: 8025-8032.

84. Lyon DE, Cohen R, Chen H, Kelly DL, Starkweather A, Ahn HC. The relationship of cognitive performance to concurrent symptoms, cancer- and cancer-treatmentrelated variables in women with early-stage breast cancer: a 2-year longitudinal study. J Cancer Res Clin Oncol 2016; 142: 1461-1474.

85. Pullens MJ, De Vries J, Roukema JA. Subjective cognitive dysfunction in breast cancer patients: a systematic review. Psychooncol 2010; 19: 1127-1138.

86. Reichenberg A, Yirmiya R, Schuld A, Kraus T, Haack M, Morag A. Cytokine-associated emotional and cognitive disturbances in humans. Arch Gen Psychiatry 2001; 58: 445-452.

87. Ganz PA, Bower JE, Kwan L, Castellon SA, Silverman DH, Geist C. Does tumor necrosis factor-alpha (TNFalpha) play a role in post-chemotherapy cerebral dysfunction? Brain Behav Immun 2013; 30: 99-108.

88. Correa DD, Ahles TA. Cognitive adverse effects of chemotherapy in breast cancer patients. Curr Opin Support Palliat Care 2007; 1: 57-62.

89. Frank JS, Vance DE, Triebel KL, Meneses KM. Cognitive deficits in breast cancer survivors after chemotherapy and hormonal therapy. J Neurosci Nurs 2015; 47: 302-312.

90. Jim HS, Donovan KA, Small BJ, Andrykowski MA, Munster PN, Jacobsen PB. Cognitive functioning in breast cancer survivors: a controlled comparison. Cancer 2009; 115: 1776-1783.

91. Ahles TA, Saykin AJ, Noll WW, Furstenberg CT, Guerin $\mathrm{S}$, Cole B. The relationship of APOE genotype to neuropsychological performance in long-term cancer survivors treated with standard dose chemotherapy. Psychooncology 2003; 12: 612-619.

92. Small BJ, Rawson KS, Walsh E, Jim HS, Hughes TF, Iser L. Catechol-O-methyltransferase genotype modulates cancer treatment-related cognitive deficits in breast cancer survivors. Cancer 2011; 117: 1369-1376.

93. George M, Elias A, Shafiei M. Insomnia in cancerassociations and implications. Asian Pac J Cancer Prev 2015; 16: 6711-6714.

94. Graci G. Pathogenesis and management of cancer-related insomnia. J Support Oncol 2005; 3: 349-359.

95. Howell D, Oliver TK, Keller-Olaman S, Davidson JR, Garland S, Samuels C. Sleep disturbance in adults with cancer: a systematic review of evidence for best practices in assessment and management for clinical practice. Ann Oncol 2014; 25: 791-800.

96. Davidson JR, MacLean AW, Brundage MD, Schulze K. Sleep disturbance in cancer patients. Soc Sci Med 2002; 54: 1309-1321.

97. Palesh OG, Roscoe JA, Mustian KM, Roth T, Savard J, Ancoli-Israel S. Prevalence, demographics, and psychological associations of sleep disruption in patients with cancer: University of Rochester Cancer CenterCommunity Clinical Oncology Program. J Clin Oncol 2010; 28: 292-298.

98. Savard J, Villa J, Ivers H, Simard S, Morin CM. Prevalence, natural course, and risk factors of insomnia comorbid with cancer over a 2 -month period. J Clin Oncol 2009; 27: 5233-5239.

99. Lee K, Cho M, Miaskowski C, Dodd M. Impaired sleep and rhythms in persons with cancer. Sleep Med Rev 2004; 8: $199-212.0$

100. Szentkiralyi A, Madarasz CZ, Novak M. Sleep disorders: impact on daytime functioning and quality of life. Expert Rev Pharmacoecon Outcomes Res 2009; 9: 49-64.

101. Miaskowski C, Dodd M, Lee K, West C, Paul SM, Cooper BA. Preliminary evidence of an association between a functional interleukin-6 polymorphism and fatigue and sleep disturbance in oncology patients and their family caregivers. J Pain Symptom Manage 2010; 40: 531-544.

102. Miaskowski C, Cooper BA, Dhruva A, Dunn LB, Langford DJ, Cataldo JK. Evidence of associations between cytokine genes and subjective reports of sleep disturbance in oncology patients and their family caregivers. PLoS One 2012; 7: 40560.

103. Alfaro E, Dhruva A, Langford DJ, Koetters T, Merriman JD, West C. Associations between cytokine gene variations and self-reported sleep disturbance in women following breast cancer surgery. Off J Eur Oncol Nurs Soc 2014; 18: 85-93.

104. Andersen KG, Kehlet H. Persistent pain after breast cancer treatment: a critical review of risk factors and strategies for prevention. J Pain 2011; 12: 725-746.

105. Harmon D, Holmes L. Persistent pain after breast cancer surgery. Pain 2016; 157: 2141. 
106. Knobf T. Five to seven years after breast cancer treatment, over a third of women (37\%) report persistent pain. Evid Based Nurs 2014; 17: 41-42.

107. Hickey OT, Burke SM, Hafeez P, Mudrakouski AL, Hayes ID, Shorten GD. Severity of acute pain after breast surgery is associated with the likelihood of subsequently developing persistent pain. Clin J Pain 2010; 26: 556-560.

108. Grivennikov SI, Karin M. Inflammatory cytokines in cancer: tumour necrosis factor and interleukin 6 take the stage. Ann Rheum Dis 2011; 70: 104-108.

109. Hanahan D, Weinberg RA. Hallmarks of cancer: the next generation. Cell 2011; 144: 646-674.

110. Dai X, Xiang L, Li T, Bai Z. Cancer hallmarks, biomarkers and breast cancer molecular subtypes. J Cancer 2016; 7: 1281-1294.

111. Li N, Grivennikov SI, Karin M. The unholy trinity: inflammation, cytokines, and STAT3 shape the cancer microenvironment. Cancer Cell 2011; 19: 429-431.

112. Jung BF, Ahrendt GM, Oaklander AL, Dworkin RH. Neuropathic pain following breast cancer surgery: proposed classification and research update. Pain 2003; 104: 1-13.

113. Gartner R, Jensen MB, Nielsen J, Ewertz M, Kroman N, Kehlet $H$. Prevalence of and factors associated with persistent pain following breast cancer surgery. JAMA 2009; 302: 1985-1992.

114. Carpenter JS, Andrykowski MA, Sloan P, Cunningham L, Cordova MJ, Studts JL. Postmastectomy/postlumpectomy pain in breast cancer survivors. J Clin Epidemiol. 1998; 51: 1285-1292.

115. Peuckmann V, Ekholm O, Rasmussen NK, Groenvold M, Christiansen P, Moller S. Chronic pain and other sequelae in long-term breast cancer survivors: nationwide survey in Denmark. Eur J Pain 2009; 13: 478-485.

116. Steegers MA, Wolters B, Evers AW, Strobbe L, WilderSmith OH. Effect of axillary lymph node dissection on prevalence and intensity of chronic and phantom pain after breast cancer surgery. J Pain 2008; 9: 813-822.

117. McCann B, Miaskowski C, Koetters T, Baggott C, West $\mathrm{C}$, Levine JD. Associations between pro- and antiinflammatory cytokine genes and breast pain in women prior to breast cancer surgery. J Pain 2012; 13: 425-437.

118. Stephens K, Cooper BA, West C, Paul SM, Baggott CR, Merriman JD. Associations between cytokine gene variations and severe persistent breast pain in women following breast cancer surgery. J Pain 2014; 15: 169-180.

119. Remmers EF, Cosan F, Kirino Y, Ombrello MJ, Abaci N, Satorius C. Genome-wide association study identifies variants in the MHC class I, IL10, and IL23R-IL12RB2 regions associated with Behcets disease. Nat Genet 2010; 42: 698-702.

120. Abhimanyu, Mangangcha IR, Jha P, Arora K, Mukerji M, Banavaliker JN. Differential serum cytokine levels are associated with cytokine gene polymorphisms in north Indians with active pulmonary tuberculosis. Infect Genet Evol 2011; 11: 1015-1022.

121. Wang AH, Lam WJ, Han DY, Ding Y, Hu R, Fraser AG. The effect of IL-10 genetic variation and interleukin 10 serum levels on Crohns disease susceptibility in a New Zealand population. Hum Immunol 2011; 72: 431-435.

122. Qaddourah RH, Magdoud K, Saldanha FL, Mahmood N, Mustafa FE, Mahjoub T. IL-10 gene promoter and intron polymorphisms and changes in IL-10 secretion in women with idiopathic recurrent miscarriage. Hum Reprod 2014; 29: 1025-1034.

123. Langford DJ, West C, Elboim C, Cooper BA, Abrams G, Paul SM. Variations in potassium channel genes are associated with breast pain in women prior to breast cancer surgery. J Neurogenet 2014; 28: 122-135.

124. Langford DJ, Paul SM, West CM, Dunn LB, Levine JD, Kober KM. Variations in potassium channel genes are associated with distinct trajectories of persistent breast pain after breast cancer surgery. Pain 2015; 156: 371-380.

125. Conley S. Symptom cluster research with biomarkers and genetics using latent class analysis. West J Nurs Res 2016.

126. Lynch Kelly D, Dickinson K, Hsiao CP, Lukkahatai N, Gonzalez-Marrero V, McCabe M. Biological basis for the clustering of symptoms. Semin Oncol Nurs 2016; 32: 351-360.

127. Illi J, Miaskowski C, Cooper B, Levine JD, Dunn L, West C. Association between pro- and anti-inflammatory cytokine genes and a symptom cluster of pain, fatigue, sleep disturbance, and depression. Cytokine 2012; 58: 437-447.

128. Doong SH, Dhruva A, Dunn LB, West C, Paul SM, Cooper BA. Associations between cytokine genes and a symptom cluster of pain, fatigue, sleep disturbance, and depression in patients prior to breast cancer surgery. Biol Res Nurs 2015; 17: 237-247.

\section{*Correspondence to}

Murtala B. Abubakar

Human Genome Centre

School of Medical Sciences

Universiti Sains Malaysia

Malaysia 